\title{
Analytical indicators to characterize Particulate Organic Matter (POM) and its evolution in French Vertical Flow Constructed Wetlands (VFCWs)
}

\author{
M. Kania ${ }^{a, b}$, M. Gautier ${ }^{\mathrm{a}}$, J. Liu' ${ }^{\mathrm{c}}$, Z. Nic ${ }^{\mathrm{c}}$ P. James ${ }^{\mathrm{d}}$, E. Bonjour ${ }^{\mathrm{d}}$, R. Guégan ${ }^{\mathrm{e}}$, P. Michel ${ }^{\mathrm{b}}$ \\ and R. Gourdon ${ }^{\mathrm{a}}$
}

${ }^{a}$ Univ Lyon, INSA Lyon, DEEP, 20 av. Albert Einstein, 69621 Villeurbanne Cedex, France manon.kania@insa-lyon.fr ; mathieu.gautier@insa-lyon.fr ;remy.gourdon@insa-lyon.fr

${ }^{b}$ SCIRPE, 5 Allée Alban Vistel, 69110 Sainte-Foy-Lès-Lyon, France, pmi@ scirpe.fr

${ }^{c}$ Laboratory for Solid Waste Management and Environment Safety, Ministry of Education of China, Tsinghua University, Beijing 10084, China, jgliu@tsinghua.edu.cn;

${ }^{d}$ Univ Lyon, CNRS, Université Claude Bernard Lyon 1, Ens de Lyon, Institut des Sciences Analytiques, UMR 5280, 5 rue de la Doua, F-69100 Villeurbanne, France, patrick.jame@isa-lyon.fr ; erik.bonjour@isa-lyon.fr; anthony.anchisi@isa-lyon.fr

'Institut des Sciences de la Terre d'Orléans, UMR 7327, CNRS-Université d'Orléans, 1 A rue de la Ferolerie, 45071 Orléans Cedex 2, France, regis.guegan@univ-orleans.fr

\begin{abstract}
The design of French Vertical Flow Constructed Wetlands (VFCWs) lead to the formation of a sludge blanket at the surface of the first-stage filter-cells. This study combined several approaches to analyze suspended solids and sludge deposits taken from two real-scale plants treating domestic wastewater through a process chain including an aerobic biological trickling filter followed by $\mathrm{FeCl}_{3}$ injection and two successive stages of VFCW. The objectives were to assess the evolution of POM along the treatment steps, the effect of ageing within the surface sludge blanket, and to identify relevant analytical indicators of these phenomena.
\end{abstract}

Thermal analyses showed that the organic matter contents in the suspended solids significantly decreased with the treatment steps. POM in inflow suspended solids was predominantly composed of reactive, biodegradable compounds which were partly hydrolyzed and mineralized notably by the trickling filter. The residual POM, proportionally enriched in more stable compounds underwent a humifaction process during its ageing within the surface sludge 
blanket, which was confirmed through.3D fluorescence data. FTIR pointed out the mineralization process of the reactive constituents of POM with the decrease in the intensities of the characteristics bands of aliphatic compounds or proteins. while the humification of POM was also stresses out through the relative increase of the bands at $1634 \mathrm{~cm}^{-1}\left(\mathrm{v}_{\mathrm{C}=\mathrm{O}}\right)$ and 1238 $\mathrm{cm}^{-1}\left(\delta_{\mathrm{C}=\mathrm{O}}\right.$ and/or $\left.\delta \mathrm{OH}\right)$. Isotopic ratios $\delta^{2} \mathrm{H} /{ }^{1} \mathrm{H}$ and $\delta^{15} \mathrm{~N} /{ }^{14} \mathrm{~N}$ were found to be better indicators of POM evolutions. The increase of $\delta^{2} \mathrm{H} /{ }^{1} \mathrm{H}$ observed in POM from the inflow suspended solids to the sludge deposits was considered to provide an additional evidence of humification. The increase of $\delta^{15} \mathrm{~N} /{ }^{14} \mathrm{~N}$ was a good indicator of the microbial processes of POM hydrolysis and mineralization.

\section{Keywords}

Suspended solid; sludge deposit; humification ; mineralization ; thermal analysis ; isotopic ratio ; 3D fluorescence ; infrared spectrocopy 


\section{Graphical Abstract}

\section{Highlights}

- $\mathrm{POM}$ in inlet wastewater contains predominantly readily biodegradable compounds

- Along the treatment chain, POM is hydrolyzed and partially mineralized, and the residual fraction is progressively humified

- Thermal analyses provide relevant information on POM mineralization

- 3D fluorescence EEM spectroscopy is relevant to assess humification but requires a preliminary step of extraction

- Isotopic ratios, notably $\delta^{15} \mathrm{~N}$, are good indicators of biological processes of POM evolutions 


\section{Introduction}

Constructed wetlands have become over the last decade the number-one technology used by small communities in France for the treatment of domestic wastewaters. The so-called "French system" composed of two successive stages of vertical-flow filters fed with un-settled wastewater is by far predominant in France. The first-stage filter usually comprises 3 cells which are alternatively fed for a week and rested for two weeks. Suspended solids are thereby progressively accumulated by filtration at the surface of the first-stage filter cells in the form of a sludge blanket. Recent studies have revealed the positive roles of this layer in suspended solids retention and dissolved pollutants sorption and/or degradation (Kim et al., 2013; Kim et al., 2014; Molle, 2014). Fu et al. (2015)(Fu et al., 2015) showed that spreading sludge deposits taken from a mature plant at the surface of the first-stage filters of a newly installed plant improved greatly the startup performance of the new plant. However in practice, excessive accumulation of sludge deposits is considered to reduce permeability and thereby alter the performance of the system. Yet, clogging has been observed in some relatively young plants where sludge blanket's thickness is small whereas older plants with thicker sludge blankets may not exhibit clogging. Various causes related to plants design, environmental factors, construction and /or operational conditions may explain these different patterns of evolution. Published data on sludge blanket concern mostly quantitative parameters such as thickness, humidity and organic matter contents. Compositional and structural parameters have rarely been considered, both in practice and in scientific publications, although they might have strong influence on clogging issues.

Several analytical methods are available to characterize the structure and composition of organic matter from natural origin, such as thermogravimetric analysis (TGA-DSC), Fouriertransform infrared (FT-IR) spectroscopy, ultraviolet/visible (UV/vis) spectroscopy, fluorescence excitation/emission (EEM) spectroscopy, and nuclear magnetic resonance (NMR) 
(Chen et al., 2003; Gomez et al., 2007; Gomez et al., 2005; Sheng \& Yu, 2006; Wei et al., 2016; Zahra El Ouaqoudi et al., 2015). In a previous paper, we reported comparative data of particle size distribution and aggregation in sludge deposits taken from 14 VFCW plants operated in France with different types of design and treatment processes (Kania et al, 2017). The present article investigated the characteristics of organic matter in wastewater suspended solids and in sludge deposits, using complementary techniques selected for their relevance, non-destructive nature, relative simplicity and rapidity (Baccot, 2016; Kogel-Knabner, 2000). Wastewater suspended solids were sampled at different stages along the treatment chain and sludge deposits were sampled from the sludge blanket at the surface of the first-stage filters of two French VFCW plants of different ages. The objectives were to assess the factors governing the evolution of wastewater particulate organic matter in French VFCW systems and evaluate the effects of ageing within the sludge blanket.

\section{Materials and Methods}

\subsection{Origins of the samples}

Particulate organic materials were taken from two French VFCW plants of similar sizes (around 1000 population equivalent) and designs, treating mostly domestic wastewater. The plants were located in the middle-eastern part of France, respectively in Vercia (Jura) and Cormatin (Saône et Loire), and referenced here as VER and COR. Both plants were designed and operated according to the AZOE-NP ${ }^{\circledR}$ process patented by the French company SCIRPE in 2003 and illustrated in Figure 1. The system combined successively (i) a sieving and gridding operation to remove coarse debris and particles, (ii) a biological treatment on an aerobic trickling filter to treat organic load and promote nitrification, (iii) $\mathrm{FeCl}_{3}$ injection to precipitate phosphates, and (iv) two successive French VFCW stages respectively made of three and two alternatively fed filter cells. The levels of water-saturation in the filter-cells was adjustable to allow nitrification in the upper vadose zone and denitrification in the lower saturated zone. 
The major difference between the two selected plants was in their number of years of operation. Vercia plant (VER) was started in 2004 as the first AZOE-NP ${ }^{\circledR}$ plant put in operation, whereas Cormatin (COR) was started in 2015.

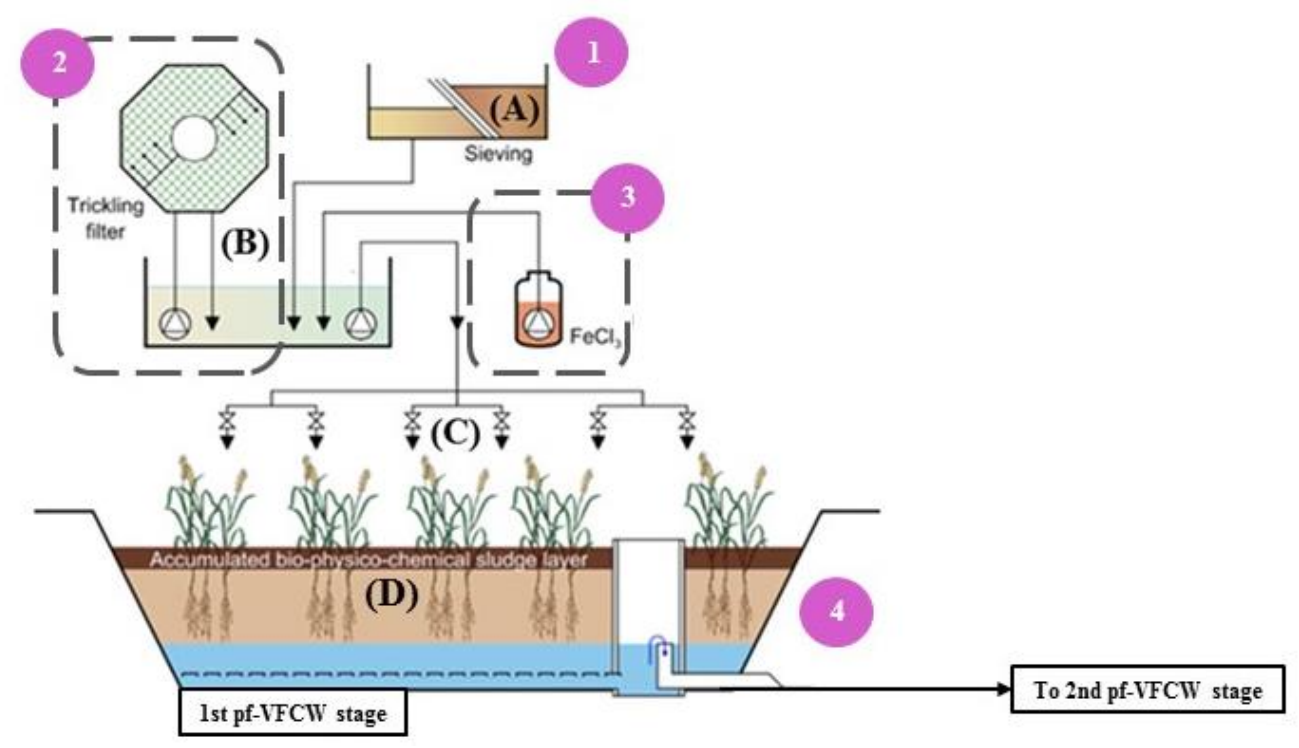

Fig. 1: Simplified diagram of AZOE-NP ${ }^{\circledR}$ process in the selected French VFCW plants.

The numbers show the successive stages of the treatment line: [1] Gridding / sieving; [2] aerobic biological trickling filter; [3] $\mathrm{FeCl}_{3}$ injection, and [4] first stage filter cells.

The letters show the locations of the sampling spots, as explained in Table 1

\subsection{Sampling and samples preparation}

Inflow suspended solids, denoted $\mathrm{SS}_{\mathrm{i}}$, were collected from wastewater feed by sieving at $0.45 \mu \mathrm{m}$ the aqueous suspensions sampled from the inlet of each plant (spot (A) in Fig. 1). In COR plant, suspended solids were also collected at different stages along the process line as shown in Fig. 1. This was not technically feasible in VER plant. Suspended solids denoted SSTF were collected from the outlet of the trickling filter (spot B), and solids SSTF-Fe were collected from the wastewater spread at the surface of the first-stage filters (i.e. after $\mathrm{FeCl}_{3}$ injection, spot $\mathrm{C}$ in Fig. 1). The solids were recovered from the sieves using a small volume of the suspension of origin, and the concentrated suspensions were then taken to the laboratory where they were centrifuged. 
Sludge deposits, denoted SD, were taken from the surface sludge blanket of the first-stage filter cell in each plant (D in Fig. 1). The whole depth of the sludge blankets was sampled from about 10 spots randomly distributed over the surface of the filter cells. Samples from each spot were treated onsite to extract manually reeds' rhizomes and gravels, and finally mixed together to constitute the overall sample representative of the whole surface layer of the considered plant. Table 1 summarizes the different types of samples taken from each plant.

All samples (suspended solids SS and sludge deposits SD, respectively) were brought to the laboratory within a maximum of 4 hours. An aliquot of each sample was directly analyzed to determine humidity by drying at $105^{\circ} \mathrm{C}$ until constant mass.

Table 1: Origins of the samples from VER and COR treatment plants

\begin{tabular}{c|cccc}
\hline Plants' references & \multicolumn{4}{|c}{ Samples' references } \\
\hline & SS $_{\mathbf{i}}$ & SS $_{\text {TF }}$ & SS $_{\text {TF-Fe }}$ & SD \\
\hline VER & A & & & D \\
COR & A & B & C & D \\
\hline
\end{tabular}

\subsection{General characterization of organic matter}

The particulate organic matter of the suspended solids and sludge deposits samples was firstly characterized with respect to general properties, namely its reactivity to thermal oxidative treatment and its extractability into aqueous solutions.

\subsubsection{Thermogravimetric and differential thermal analysis (TGA / DTA)}

Thermo-gravimetric methods have been used by many authors in various objectives, for example to monitor the aerobic bio-stabilization of activated sludge or the composting of yard waste or municipal solid wastes organic fractions (Otero et al., 2002).

Analyses were carried out using a METTLER TOLEDO TGA/DTA thermogravimetric simultaneous thermal analyzer whose temperature precision was $\pm 0.5^{\circ} \mathrm{C}$ and microbalance 
sensitivity less than $\pm 0.1 \mathrm{mg}$. A dry mass of $20 \mathrm{mg}$ of each sample was heated from $35^{\circ} \mathrm{C}$ to $900^{\circ} \mathrm{C}$ at a rate of $10^{\circ} \mathrm{C} / \mathrm{min}$, under a flow of air of $50 \mathrm{~mL}$ per minute. Several blank experiments were carried under the same conditions as the assays but without any sample.

Organic matter contents $(\mathrm{OM})$ of samples were obtained by measuring the mass loss of the samples between 200 and $600{ }^{\circ} \mathrm{C}$ (Som et al., 2009).

\subsubsection{Organic matter extractability}

A fractionation method was used to assess the extractability of the particulate organic matter from the different samples. The method consisted in successive extractions of organic constituents into aqueous solutions of different natures. It was adapted from the protocol proposed by Jimenez et al., 2015(Jimenez et al., 2015). A dry mass of $0.5 \mathrm{~g}$ of each solid sample prepared as detailed above was treated according to the following steps:

- Step 1: 4 extractions of 15 min with $30 \mathrm{~mL}$ of a $10 \mathrm{mM} \mathrm{CaCl}_{2}$ aqueous solution,

- Step 2: 4 extractions of $15 \mathrm{~min}$ with $30 \mathrm{~mL}$ of $10 \mathrm{mM} \mathrm{NaCl}+10 \mathrm{mM} \mathrm{NaOH}$ aqueous solution, - Step 3: 4 extractions of $4 \mathrm{~h}$ with $30 \mathrm{~mL}$ of $1 \mathrm{M} \mathrm{NaOH}$ aqueous solution, under $\mathrm{N}_{2}$ atmosphere - Step 4: 2 extractions of $3 \mathrm{~h}$ with $25 \mathrm{~mL}$ of a $72 \%$ w/w $\mathrm{H}_{2} \mathrm{SO}_{4}$ aqueous solution.

All samples were treated in triplicates. Extractions were carried out in an orbital shaker at room temperature. Following each sequence of extraction, the solids were separated from the solutions by $15 \mathrm{~min}$ of centrifugation at $10000 \mathrm{~g}$ and $4^{\circ} \mathrm{C}$. For each sample and replicate, the supernatants obtained from each step of the protocol were mixed together, filtered at $0.45 \mu \mathrm{m}$ on cellulose acetate filters and analyzed for dissolved organic carbon. The organic fractions thereby collected were referenced to as soluble organic matter (SPOM, step 1), readily extractable organic matter (REOM, step 2), slowly extractable organic matter (SEOM, step 3) and hardly extractable organic matter (HEOM, step 4), respectively.

\subsection{Molecular analyses of organic constituents}




\subsubsection{D Fluorescence EEM spectroscopy}

Each extract obtained from the fractionation of inflow suspended solids $\mathrm{SS}_{\mathrm{i}}$ and sludge deposits SD from both plants was analyzed by 3D Fluorescence Excitation Emission Matrix (EEM) spectroscopy. Analyses were done using a Hitachi F-7000 fluorescence spectrometer operated at room temperature. The slit widths were set to $5 \mathrm{~nm}$ for the excitation and emission monochromators, and the scan speed was set to $12,000 \mathrm{~nm} / \mathrm{min}$. EEM spectra were gathered with the subsequent scanning emission spectra (Em) from 200 to $500 \mathrm{~nm}$ at $5 \mathrm{~nm}$ increments by varying the excitation wavelength (Ex) from 200 to $450 \mathrm{~nm}$ at $5 \mathrm{~nm}$ increments. Filtered aqueous solutions obtained from the sequential fractionation protocol described above were diluted with deionized water to a TOC concentration of ca. $5 \mathrm{mg} / \mathrm{L}$ before EEM spectroscopy analyses. All samples were analyzed in triplicates. Blank spectra were obtained by analyzing de-ionized water, and subtracted from the samples spectra.

Resulting spectra were usually exploited by considering five or more regions with specific excitation and emission wavelength boundaries considered representative of different categories of organic constituents as illustrated in Fig. 2 (Chen et al., 2003; He et al., 2011; Jimenez et al., 2014). Regions I and II were associated to various amino acids (notably aromatic amino-acids such as tyrosine) and peptides, Region IV to proteins-like substances and small size compounds such as microbial metabolites. Regions III and V were reported to be related respectively to complex aromatic phenolic acids such as ligno-cellulosic complexes, fulvic-like acids or similar compounds, and humic-like acids or related compounds (complex polyaromatic acids of high molecular size). 


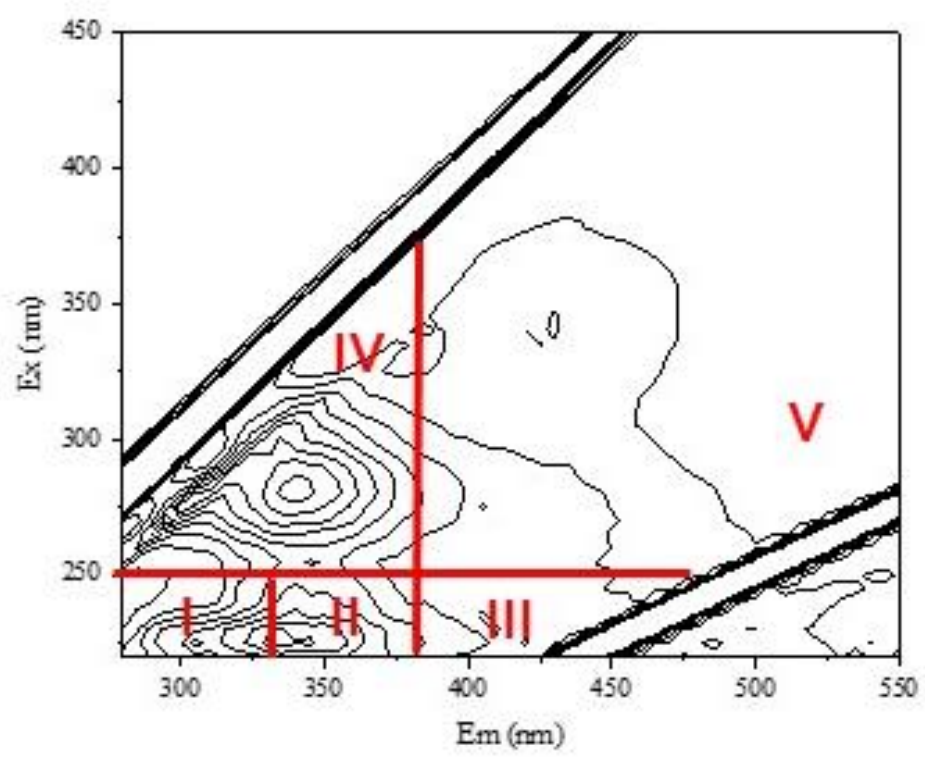

Fig. 2: Illustration of the regions defined to exploit 3D EEM fluorescence spectra with associated types of organic constituents (after Chen et al., 2003; He et al., 2011; Jimenez et al., 2014). Regions I and II correspond to aromatic amino-acids, peptides and related compounds; Region III to fulvic-like acids; Region IV to low-molecular size compounds such as microbial metabolites, proteins and related compounds, and Region $\mathrm{V}$ corresponds to lignocellulosic and humic-like acids

\subsubsection{Infrared spectroscopy}

Fourier Transform InfraRed (FTIR) spectrometry was used to probe the functional groups related to the organic matter, present in the sludge.

FTIR spectra were collected from dry powder samples using a Thermo Nicolet 6700 spectrometer equipped with Germanium attenuated total reflection (ATR) and deuterated triglycine sulfate (DTGS) detectors. Each spectrum was obtained as the average of 128 scans in the range of $400-4000 \mathrm{~cm}^{-1}$ with a spectral resolution of $2 \mathrm{~cm}^{-1}$.

\subsubsection{Isotopic analyses}

${ }^{15} \mathrm{~N} /{ }^{14} \mathrm{~N}$ and ${ }^{13} \mathrm{C} /{ }^{12} \mathrm{C}$ isotope ratios were analyzed simultaneously using a Thermo Flash EA1112 Elemental Analyzer linked to a Delta V Plus Isotope-Ratio Mass Spectrometer (EA-IRMS) via a Conflo IV interface (all Thermo Fisher Scientific, Bremen, Germany). All analyses were duplicated. About one $\mathrm{mg}$ of sample was deposited into tin capsules and placed in the combustion unit set at $950^{\circ} \mathrm{C}$ and circulated with a flow of helium at $90 \mathrm{~mL} \cdot \mathrm{min}^{-1}$ spiked with 
di-oxygen. Particulate carbon and nitrogen were thereby transformed into $\mathrm{CO}_{2}$ and $\mathrm{NO}_{\mathrm{x}}$ respectively, and carried by the vector gas flow, firstly through a copper reduction furnace set at $650^{\circ} \mathrm{C}$ where nitrogen was reduced into $\mathrm{N}_{2}$ and excess di-oxygen was trapped, secondly through a water trap containing anhydrous magnesium perchlorate. $\mathrm{N}_{2}$ and $\mathrm{CO}_{2}$ were then separated using a gas chromatographic column.

$\mathrm{N}$ isotopes were detected from $\mathrm{N}_{2}$ gas using the signals collected at masses 28,29 and $30 . \mathrm{C}$ isotopes were measured in $\mathrm{CO}_{2}$ gas using signals collected at masses 44,45 and 46.

${ }^{15} \mathrm{~N} /{ }^{14} \mathrm{~N}$ and ${ }^{13} \mathrm{C} /{ }^{12} \mathrm{C}$ isotopic ratios were expressed in Delta unit with respect to international standards according to the following formula shown for ${ }^{13} \mathrm{C} /{ }^{12} \mathrm{C}$ ratio:

$$
\delta\left({ }^{13} C /{ }^{12} C\right)=\left[\frac{R\left({ }^{13} C /{ }^{12} C\right) \text { sample }}{R\left({ }^{13} C /{ }^{12} C\right) \text { standard }}-1\right]
$$

The considered standards were Vienna Pee Dee Belemnite (VPDB calcium carbonate) and atmospheric $\mathrm{N}_{2}$ for $\delta^{13} \mathrm{C}$ and $\delta^{15} \mathrm{~N}$ analyses, respectively.

Reference standards IAEA CH-7 polyethylene foil $\left(\delta^{13} \mathrm{C}=-31.82 \%\right.$ ) and USGS 40 L Glutamic acid $\left(\delta^{13} \mathrm{C}=-26.39 \%, \delta^{15} \mathrm{~N}=-4.56 \%\right.$ ) supplied by the International Atomic Energy Agency (IAEA, Vienna, Austria) were regularly analyzed as controls. L Valine $\left(\delta^{15} \mathrm{~N}=-4.56 \%\right)$ was also used as an additional standard. Uncertainties on $\delta^{13} \mathrm{C}$ and $\delta^{15} \mathrm{~N}$ measurements were estimated to less than $0.3 \%$.

${ }^{2} \mathrm{H} /{ }^{1} \mathrm{H}$ isotope ratio was analyzed using a Thermo Finnigan TC/EA High Temperature Conversion Elemental analyzer (TC/EA) connected to a Thermo Delta V plus isotope-ratio mass spectrometer (Thermo Fisher Scientific, Bremen, Germany). Each analysis was duplicated. A mass of 200 to $400 \mu \mathrm{g}$ of dry powder sample was introduced into the pyrolysis unit set at $1450^{\circ} \mathrm{C}$. This unit consisted in an internal glassy carbon tube partly filled with black carbon granules incorporated into an external alumina tube and circulated with helium at a flow of 80 
$\mathrm{mL} \cdot \mathrm{min}^{-1} . \mathrm{H}_{2}$ gas produced from the pyrolysis of the sample was then transferred into the isotope-ratio mass spectrometer (IRMS) via a Conflo V interface (Thermo Fisher Scientific). $\delta^{2} \mathrm{H}$ ratios were expressed in Delta unit with respect to Vienna Standard Mean Ocean Water (VSMOW) considered as the international standard.-IAEA CH-7 polyethylene foil $\left(\delta^{2} \mathrm{H}=-\right.$ $100.3 \%$ ) was analyzed as a standard every eight samples to control the efficiency of the pyrolytic conversion. Uncertainties on $\delta^{2} \mathrm{H}$ measurements were estimated to less than $5 \%$.

\section{Results and Discussion}

\subsection{Thermal analyses}

Figure 3 shows the DTG and DSC profiles obtained from the analyses of inflow suspended solids $\left(\mathrm{SS}_{\mathrm{i}}\right)$ and surface sludge deposits (SD) sampled from the selected plants. Although the assays were monitored from room temperature to $900^{\circ} \mathrm{C}$, the graphs were represented only between $200^{\circ}$ and $600^{\circ} \mathrm{C}$, which is known as the range of temperatures inducing thermal degradation of organic polymers of natural origins (Torres-Climent et al., 2015). Data recorded below $200^{\circ} \mathrm{C}$ and above $600^{\circ} \mathrm{C}$ were not shown because they induced respectively water evaporation and thermal degradation of mineral phases, which were considered not significant in this study.

\subsubsection{Organic matter contents}

OM contents in the suspended solids $\mathrm{SS}_{\mathrm{i}}$ calculated from the results in Figure 3 revealed values as high as $86.1 \% \mathrm{w} / \mathrm{w}$ of dry matter in VER plant and $75.8 \%$ in COR, confirming the data from previous analyses of the same samples (Kim et al., 2013). In both plants, OM contents were found to be much lower in surface sludge deposits SD than in the suspended solids $\mathrm{SS}_{\mathrm{i}}$. In COR plant, which had been in operation for less than one year when the samples were taken, the decrease in $\mathrm{OM}$ contents was limited (from $75.9 \% \mathrm{w} / \mathrm{w}$ of $\mathrm{DM}$ in $\mathrm{SS}_{\mathrm{i}}$ to $65.2 \%$ in SD). The analysis of SS collected from COR plant at the outlet of the trickling filter $\left(\mathrm{SS}_{\mathrm{TF}}\right)$ and after 
$\mathrm{FeCl}_{3}$ injection ( $\mathrm{SS}_{\mathrm{TF}-\mathrm{Fe}}$ ) revealed intermediate OM contents of $74.4 \% \mathrm{w} / \mathrm{w}$ of DM and $67.2 \%$ w / w of DM, respectively (Fig. 3 and Table 2), indicating a gradual degradation of OM along the treatment chain. In VER plant, where it was not technically possible to sample SSTF and $\mathrm{SS}_{\mathrm{TF}-\mathrm{Fe}}, \mathrm{OM}$ contents were found to be $86.1 \% \mathrm{w} / \mathrm{w}$ of DM in $\mathrm{SS}_{\mathrm{i}}$ and $59.7 \% \mathrm{w} / \mathrm{w}$ of DM in SD. The overall degradation of OM was therefore much stronger in VER plant than in COR. This observation revealed the influence of the age of the plants (11 years for VER, 1 year for COR), indicating that the hydrolysis and aerobic mineralization of particulate organic matter occurred in the suspended solids within the sludge blanket over the years of operation of the plants. The sequential feeding pattern (one week feed, two weeks rest) probably installed favorable conditions for microbial aerobic activities due to the good aeration provided by wastewater percolation and the diffusion of air from the surface. 
(a) VER
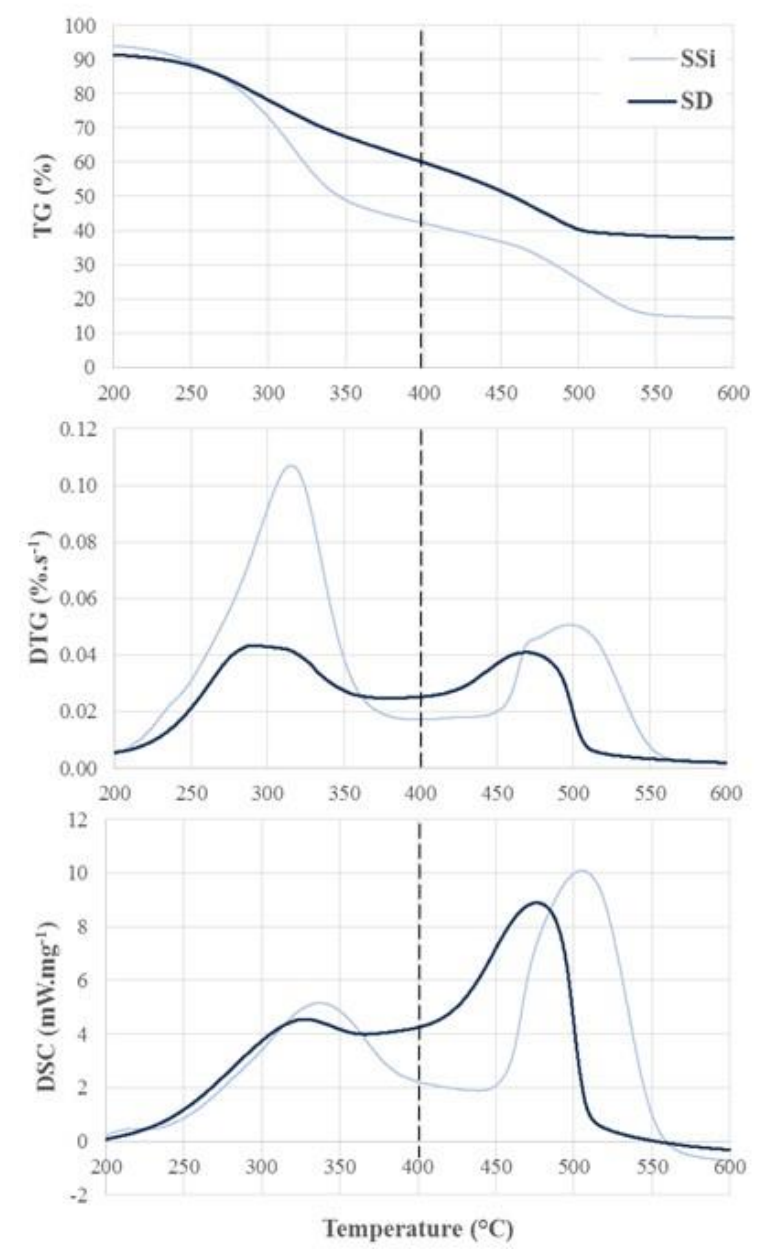

(b) $\mathrm{COR}$

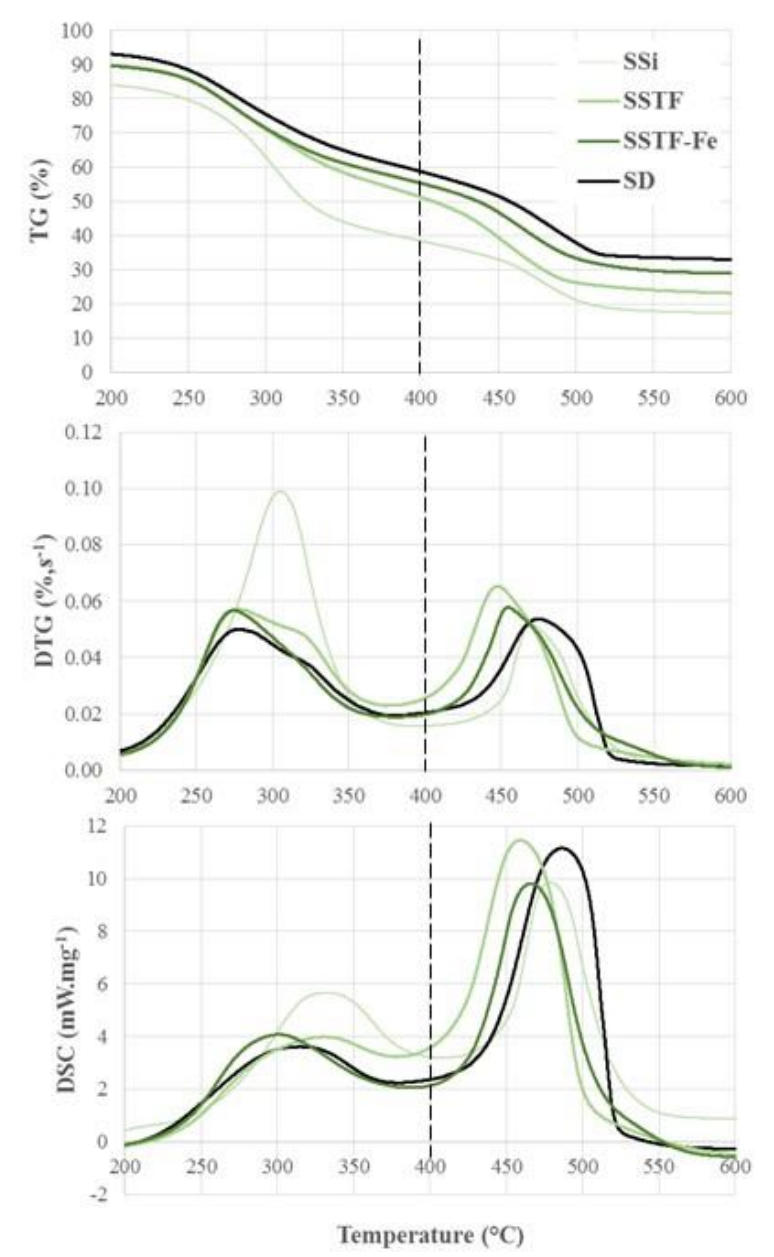

Fig. 3: Mass loss (top), DTG (middle) and DSC (bottom) profiles for the suspended solids and sludge deposits from (a) VER plant and (b) COR plant.

\subsubsection{Reactivity to oxidative thermal treatment}

The graphs shown in Fig. 3 revealed for all samples DTG and DSC profiles with two peaks corresponding to the oxidative thermal degradation of two major groups of biopolymers in the samples. The first major peak was observed at temperatures between 200 and $400^{\circ} \mathrm{C}$ with a maximum between 275 and $315^{\circ} \mathrm{C}$ corresponding to the point of inflexion of the respective mass loss curves. This peak was attributed to the thermal degradation of organic compounds of low to medium chemical stability, such as carbohydrates, aliphatic alcohols, lipids, amino acids etc., whose thermal reactivity may be considered as an indicator of their relatively good biodegradability (Chen et al., 2015; Fernandez et al., 2012; Gomez et al., 2007; Som et al., 2009; 
Zahra El Ouaqoudi et al., 2015). The second peak was observed at a temperature range of 450 to $600{ }^{\circ} \mathrm{C}$ with a maximum between 450 and $500^{\circ} \mathrm{C}$. It was attributed to the thermal degradation of more stable organic matter, potentially recalcitrant to biodegradation, such as ligno-cellulosic complexes, humic and fulvic compounds, etc. (Chen et al., 2015; Cuypers et al., 2002; Melis \& Castaldi, 2004; Torres-Climent et al., 2015; Zahra El Ouaqoudi et al., 2015). Previous studies have shown that thermal stability was well correlated to the recalcitrance to biodegradation (Bayard et al., 2005).

RTGA index was introduced as an indicator of the thermal stability of the organic matter, defined as the ratio of the mass loss recorded between 400 and $600{ }^{\circ} \mathrm{C}\left(\mathrm{m}_{\mathrm{Exo} 2}\right.$, peak2) to that recorded between 200 and $400^{\circ} \mathrm{C}$ (mExol, peak 1). For example, compost is considered mature when $\mathrm{R}_{\mathrm{TGA}}$ reaches 0.8 , while below 0.8 the humification process is considered incomplete (Som et al., 2009). Table 2 gathers the values of RTGA index calculated for all the samples analyzed here. For both plants VER and COR, it can be seen that RTGA index was around 0.4 in the inflow wastewater suspended solids $\left(\mathrm{SS}_{\mathrm{i}}\right)$ and 0.8 in suspended solids $\mathrm{SD}$. Indeed the DTG profile of inflow suspended solids $\left(\mathrm{SS}_{\mathrm{i}}\right)$ were characterized by a first peak with a higher surface area than the second one, whereas surface deposit (SD) samples showed a profile with two peaks of similar surfaces. It was concluded that the suspended solids collected from the inflow wastewaters contained a predominant proportion of thermally reactive, potentially biodegradable compounds whereas the sludge deposits collected from the surface sludge deposit contained roughly an equivalent proportion of thermally-reactive, potentially biodegradable (first peak) and thermally-stable, potentially recalcitrant (second peak) compounds. Using a similar approach, Cuypers et al. (2002) also reported that the DTG profile of samples containing highly humified, poorly biodegradable, organic matter would exhibit a small peak at temperatures around $300^{\circ} \mathrm{C}$ and a bigger one at higher temperatures around $500^{\circ} \mathrm{C}$. 
The DSC profiles showed that the thermal degradation processes were exothermic since the positive peaks in the DTG profiles were associated to positive peaks in the DSC profiles corresponding to heat releases. Fig. 3 revealed that in all the samples analyzed, the surface area ratio of the first peak in DSC profile over the first peak in DTG profile, was much smaller than for the second peaks. The thermal degradation of the organic matter associated to the first peak was therefore much less exothermic than the degradation of the constituents associated to the second peak. This observation indicated that the first peak corresponded to oxygenated organic compounds whereas the constituents associated to the second peak contained more C-C and C$\mathrm{H}$ bonds. Other authors have reported that in biomass samples, the first peak was associated to hemicelluloses and cellulose, rich in hydroxyl groups, whereas the second peak corresponded to polymers with higher $\mathrm{C}$ and $\mathrm{H}$ contents such as humic-like substances, lignin and lignocellulosic complexes (Magdziarz \& Wilk, 2013).

Table 2: $\mathbf{R}_{\mathrm{TGA}}$ index values calculated in suspended solids and sludge deposit samples from the two French VFCW plants, from the mass losses (expressed in g of dry matter) measured from 200 to $400^{\circ} \mathrm{C}\left(\mathrm{m}_{\mathrm{Exo1}}\right)$ and 400 to $600^{\circ} \mathrm{C}\left(\mathrm{m}_{\mathrm{Exo2}}\right)$

\begin{tabular}{|c|c|c|c|c|c|c|c|c|c|c|c|c|}
\hline \multirow{2}{*}{$\begin{array}{l}\text { Reference } \\
\text { of the } \\
\text { French } \\
\text { VFCW } \\
\text { plants of } \\
\text { origin }\end{array}$} & \multicolumn{3}{|c|}{$\begin{array}{c}\text { Inflow Suspended Solids } \\
\qquad \mathrm{SS}_{\mathrm{i}}\end{array}$} & \multicolumn{3}{|c|}{$\begin{array}{c}\text { SS from TF outlet } \\
\text { SS }_{\text {TF }}\end{array}$} & \multicolumn{3}{|c|}{$\begin{array}{c}\text { SS after } \mathrm{FeCl}_{3} \text { injection } \\
\mathrm{SS}_{\text {TF-Fe }}\end{array}$} & \multicolumn{3}{|c|}{$\begin{array}{c}\text { Surface sludge deposits } \\
\text { SD }\end{array}$} \\
\hline & $\mathrm{m}_{\mathrm{Exo} 1}$ & $\mathrm{~m}_{\mathrm{Exo} 2}$ & $\mathbf{R}_{\text {TGA }}$ & $\mathrm{m}_{\text {Exo1 }}$ & $\mathrm{m}_{\mathrm{Exo2}}$ & $\mathbf{R}_{\text {TGA }}$ & $\mathrm{m}_{\mathrm{Exo} 1}$ & $\mathrm{~m}_{\mathrm{Exo} 2}$ & $\mathbf{R}_{\text {TGA }}$ & $\mathrm{m}_{\mathrm{Exo1}}$ & $\mathrm{m}_{\text {Exo2 }}$ & $\mathbf{R}_{\mathrm{TGA}}$ \\
\hline VER & 13.0 & 4.7 & 0.4 & & & & & & & 7.0 & 5.3 & 0.8 \\
\hline COR & 9.6 & 4.2 & 0.4 & 7.4 & 6.4 & 0.9 & 8.3 & 5.2 & 0.6 & 7.1 & 5.6 & 0.8 \\
\hline
\end{tabular}

DTG profiles of the suspended solids taken along the treatment chain in COR plant SS $_{\mathrm{TF}}$ and $\mathrm{SS}_{\mathrm{TF}-\mathrm{Fe}}$ respectively) were also characterized by two peaks of similar surfaces as in SD sample (Fig. 3). The first peaks (corresponding to the most reactive, oxygenated compounds) in $\mathrm{SS}_{\mathrm{TF}}$ and SSTF-Fe DTG curves were very close to each other (both in surface and temperature) and also similar to that of SD sample. Their surface areas were however much smaller than that of 
the first peak in $\mathrm{SS}_{\mathrm{i}}$ sample. Table 2 showed that $\mathrm{R}_{\mathrm{TGA}}$ index was 0.4 in the inflow suspended solids, 0.9 in the suspended solids at the outlet of the trickling filter $\left(\mathrm{SS}_{\mathrm{TF}}\right), 0.6$ after $\mathrm{FeCl}_{3}$ injection (SSTF-Fe), and 0.8 in the sludge deposits SD. It was firstly concluded that the hydrolysis and mineralization of the readily biodegradable particulate organic matter occurred mostly at the stage of the aerobic biological treatment on the trickling filter, underlining the major role of the trickling filter in the overall performance of the system. The decrease of $\mathrm{R}_{\mathrm{TGA}}$ from 0.9 to 0.6 following $\mathrm{FeCl}_{3}$ injection suggested that organic compounds of small molecular size and relatively poor stability were flocculated from the aqueous solution and collected with the SSTF already present, thereby reducing the RTGA index of SSTF-Fe. Finally, the reactive organic constituents of SSTF-Fe were progressively mineralized and / or leached during the ageing of sludge deposits within the sludge blanket, resulting in an increase in RTGA index.

\subsection{D Fluorescence EEM spectroscopy of POM extracts}

\subsubsection{POM fractionation}

Results of POM fractionation are shown in Fig. 4. It was firstly observed that the fractionation of inflow suspended solids $\mathrm{SS}_{\mathrm{i}}$ from the two plants revealed very similar results (Fig. 4a), indicating that the particulate organic matter in the inflow wastewater was of similar composition in both plants. The sludge deposits SD also revealed very similar profiles in the two plants, indicating that the overall treatment line induced very similar transformations of particulate organic matter (POM) from its initial state in inflow suspended solids to its state in sludge deposits SD. The major modification was a decrease in the "soluble" and "readily extractable" fractions SPOM and REOM. This decrease was observable in each plant both in terms of the proportions of the fractions in the overall POM (Fig. 4a) and with respect to their masses per unit mass of dry matter (Fig. 4b). These fractions were probably associated with the first peak in the DTG / DSC curves of Fig. 3. Due to their relatively good biodegradability and 
extractability, their organic constituents were probably hydrolyzed, mineralized and/or leached out from the POM once accumulated in the form of SD at the surface of the VFCW filter cells. The mass of "hardly extractable fraction" HEOM was also found to decrease, particularly in VER plant (Fig. 4b), but proportionally less than SPOM and REOM fractions. Consequently, the proportion of HEOM fraction in the overall POM was found to remain similar in $\mathrm{SS}_{\mathrm{i}}$ and SD samples. In COR plant, the proportion and mass of HEOM fraction was reduced by the trickling filter (TF) whereas SEOM and REOM fractions were increased and SPOM only little modified. These results confirmed the strong role of the trickling filter in the treatment. They were attributed to the combination of several coupled processes which affected simultaneously all the fractions. The detachment of microbial biofilm fragments from the TF explained in part the increase in SEOM fraction. The hydrolytic and oxidative activities of the TF induced the decrease of HEOM fraction by hydrolysis, and the resulting increase of REOM fraction. The solubilized compounds thus formed were then probably biodegraded and/or leached out from the SD within the surface sludge blanket, explaining the decrease of SPOM and REOM fractions in SD as compared to SS samples, Finally, the increase of HEOM fraction between $\mathrm{SS}_{\mathrm{TF}-\mathrm{Fe}}$ and SD samples, observed in terms of both its proportion and mass, was attributed to ageing processes of POM within the surface sludge blanket, such as (i) the mineralization and leaching of SPOM and REOM fractions, and (ii) the progressive transformation of residual organic matter into more stable and less extractable compounds on the other hand. 

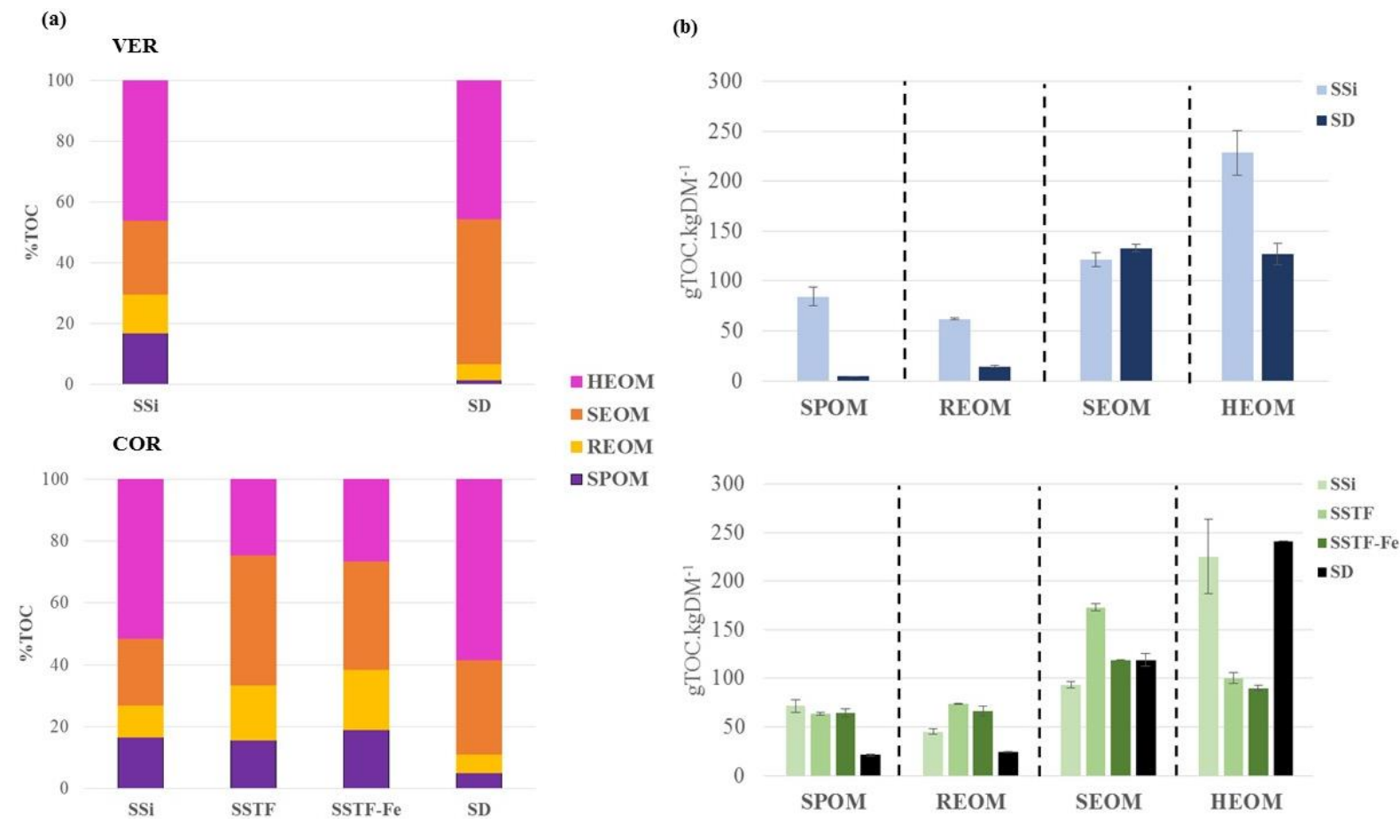

Fig. 4: Fractionation of particulate organic matter (POM) according to the extractability of its constituents in the Suspended Solids (SS) and Sludge Deposits (SD) from VER (top) and COR (bottom) French VFCW plants. Results are expressed in (a) \% w/w of cumulated extracted organic matter, and (b) in $g$ of TOC per $g$ of DM.

\subsubsection{D Fluorescence EEM spectroscopy of POM extracts}

All the aqueous extracts obtained from the fractionation steps discussed above were analyzed by 3D fluorescence EEM spectroscopy. The spectra collected from SPOM, REOM and HEOM extracts were found to be very similar to each other regardless of the nature of the samples they were obtained from. Therefore, to simplify the presentation, only a selection of the spectra are shown here. The other spectra are shown as supplementary data.

To illustrate the results here, all the spectra obtained from all extracts of VER samples are shown in Fig. 5. The spectra were all characterized by two major peaks located in regions I and/or II (peak A) and in region IV (peak B), revealing the presence of various organic constituents such as aromatic amino-acids or peptides and other low-molecular size compounds such as microbial metabolites, proteins and other biopolymers (Fig. 2). 
Unlike SPOM, REOM and HEOM extracts, the spectra collected from SEOM extract revealed significant differences in the position and intensities of peaks A and B according to the origin of the samples as shown in Fig. 5c for VER plant and Fig. 6 for COR. In this fraction, peak A was located in regions I and II in $\mathrm{SS}_{\mathrm{i}}$ samples, whereas with SD samples it was characterized by an Ex/Em wavelength pair of $284 / 383 \mathrm{~nm}$ positioned in region III. Different molecular compounds derived from lignin and other degraded plant materials have been reported to contribute to the fluorescence of fulvic-like substances in region III (Marhuenda-Egea et al., 2007). Peak B in SEOM extracts from SSi samples fell in region IV whereas in SD extracts, peak B exhibited an Ex/Em wavelength pair of $317 / 380 \mathrm{~nm}$, associated to region $\mathrm{V}$ and revealing the presence of humic-like substances and lignocellulosic complex structures (Fig. 2) (Lu et al., 2015; Wei et al., 2016). These results therefore revealed that the organic compounds extracted in SEOM fraction were globally more complex and humified in the sludge deposits than in the inflow suspended solids, suggesting a process of transformation of the low molecular weight organic constituents of inflow suspended solids into more complex, humified substances in sludge deposits.

These evolutions were observed in a similar manner in VER (Fig. 5) and COR (Fig. 6) plants, suggesting that the age of the sludge deposits, beyond 1 year of age in COR plant, did not significantly affect the degree of humifaction of their organic matter. It was concluded that one year of operation was sufficient to reach a state of relative equilibrium in the composition of the POM in the sludge deposits.

The comparison of SEOM extracts spectra in the suspended solids collected at different stages of the treatment chain in COR plant (Fig. 6) showed that the observed evolutions were predominantly induced by the stage of $\mathrm{FeCl}_{3}$ injection. Since it was shown above (Fig. $4 \mathrm{~b}$ ) that $\mathrm{FeCl}_{3}$ injection specifically reduced SEOM content, this observation may be attributed to the oxidation by $\mathrm{Fe}$ (III) of reactive organic compounds and the associated proportional increase of 
humic- and fulvic-like substances, or the formation of complex structures from more simple compounds in SEOM fraction due to the coagulating effect of $\mathrm{FeCl}_{3}$. Additionally, the increase of peak B intensity between SSTF-Fe and SD samples provided further evidence of the ageing of organic matter resulting in a higher degree of humifaction within the sludge deposits (Lv et al., 2013). 
$\mathbf{S S}_{\mathrm{i}}$
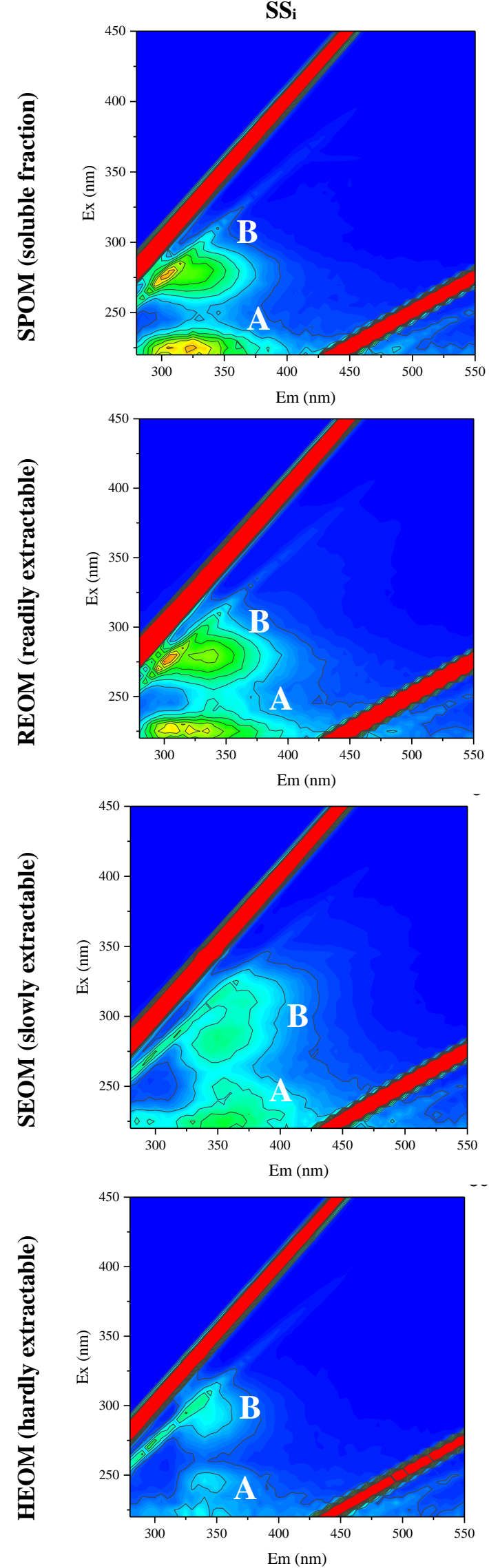

SD

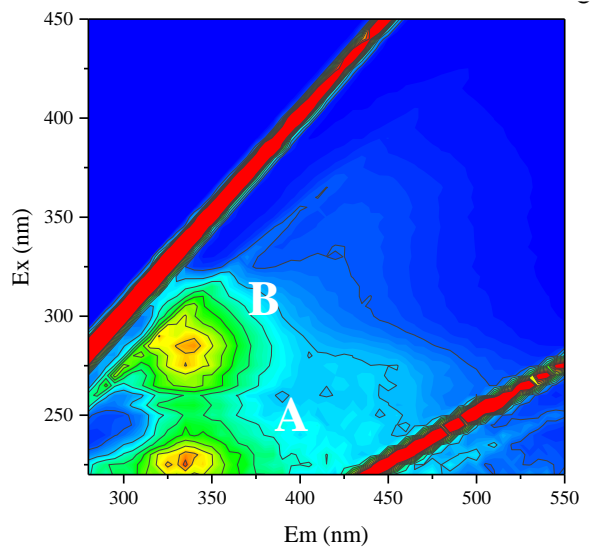

Intensity
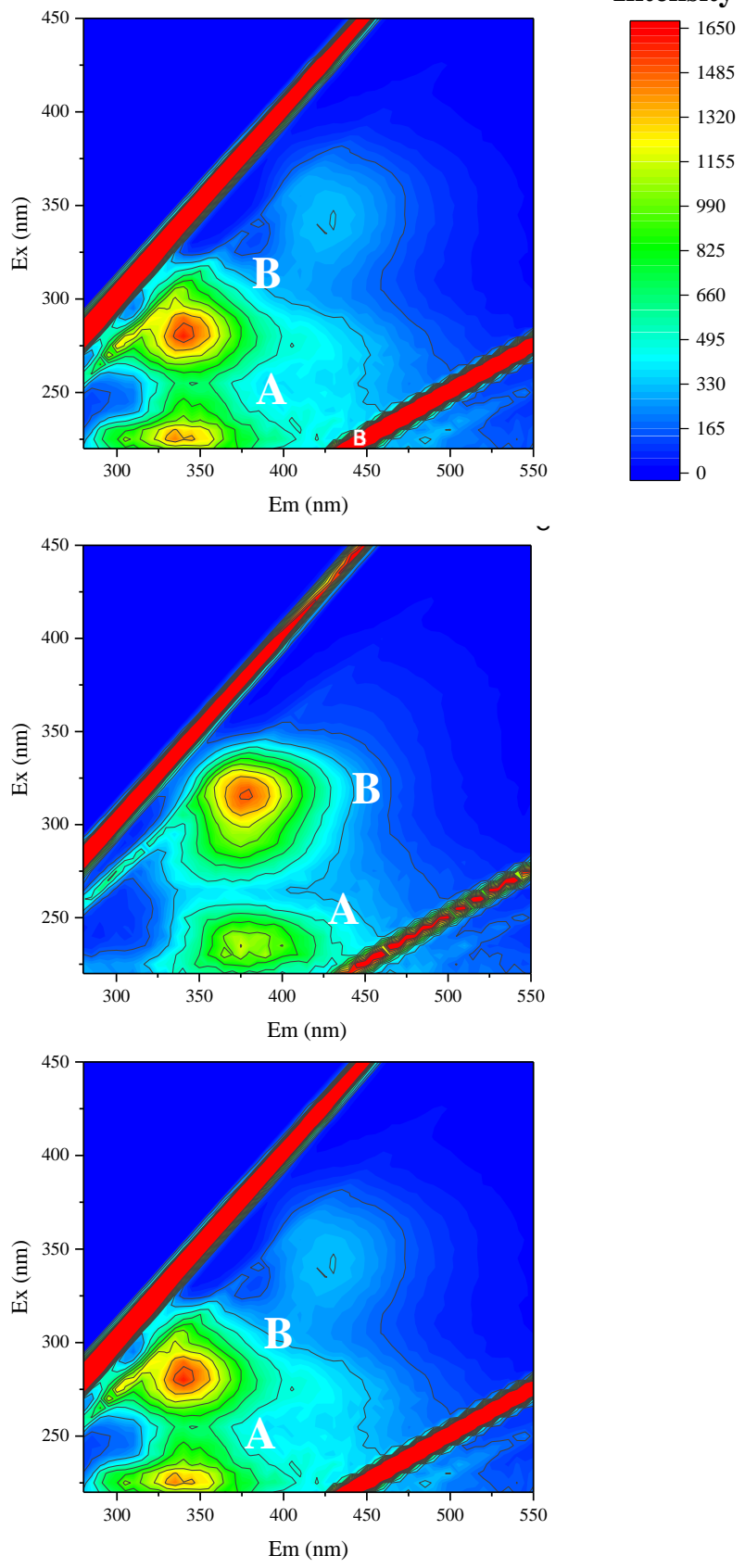

Fig. 5: 3D EEM fluorescence spectra collected from aqueous fractions of particulate organic matter (from top to bottom: (a) SPOM, (b) REOM, (c) SEOM and (d) HEOM fractions) extracted from inflow suspended solids ( $\mathrm{SS}_{\mathrm{i}}$, left) and sludge deposits (SD, right) sampled from VER plant 
$\mathbf{S S}_{\mathrm{i}}$

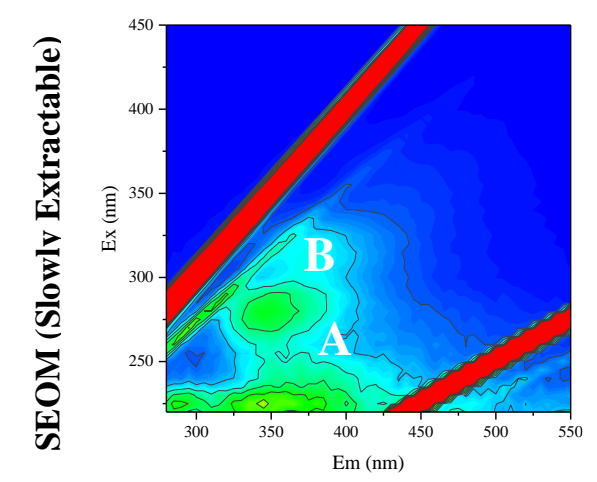

$\mathbf{S S}_{\mathrm{TF}}$

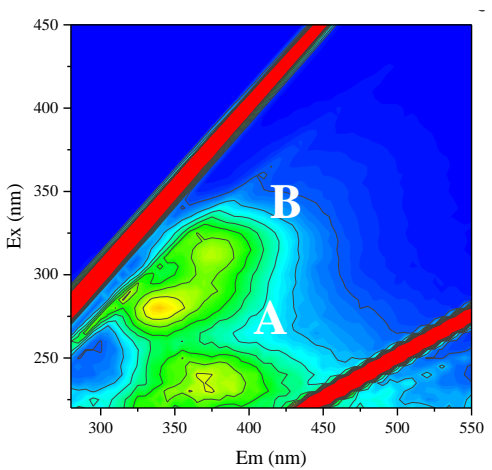

SS $_{\text {TF-Fe }}$

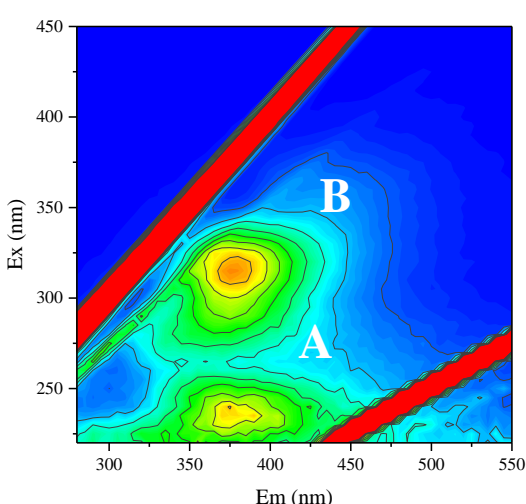

SD

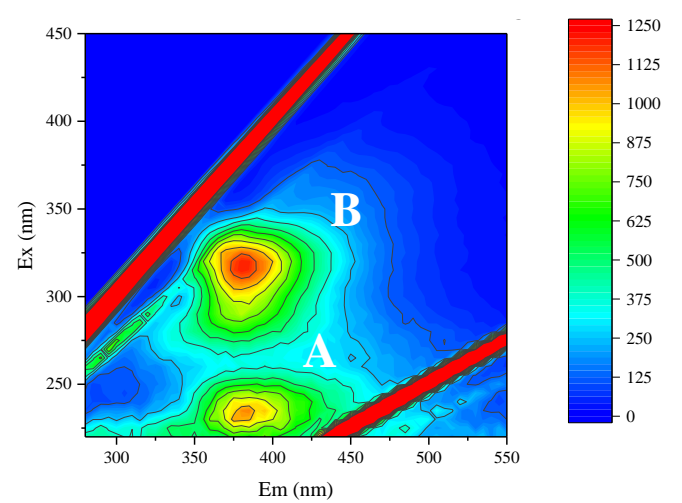

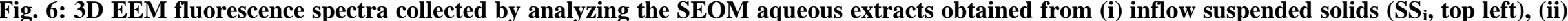
suspended solids from trickling filter outlet $\left(\mathrm{SS}_{\mathrm{TF}}\right.$ top right) and (iii) afterFeCl $\mathrm{H}_{3}$ injection ( $\mathrm{SS}_{\mathrm{TF}-\mathrm{Fe}}$, bottom left), and sludge deposits (SD, bottom right) from COR plant 


\subsection{FTIR analyses}

The FTIR spectra obtained by analyzing the inflow suspended solids and sludge deposits from each plant are shown in Fig. 7. The figure also shows the spectra collected from the suspended solids sampled at different stages of the treatment chain in COR plant ( $\mathrm{SS}_{\mathrm{TF}}$ and $\left.\mathrm{SS}_{\mathrm{TF}-\mathrm{Fe}}\right)$.
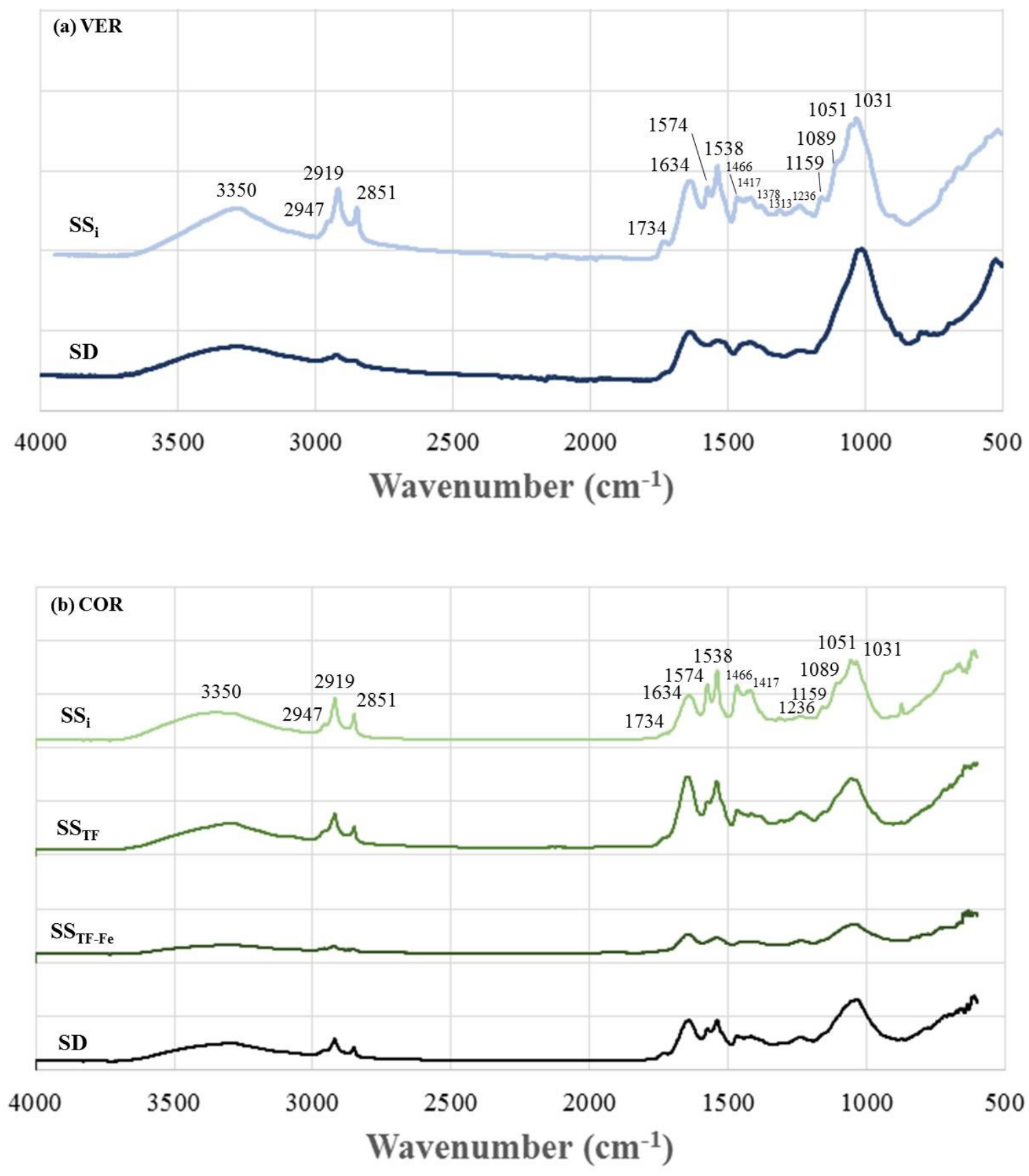

Fig. 7: FTIR spectra of: (a) VER samples with inflow suspended solids $\left(\mathbf{S S}_{\mathrm{i}}\right)$ and sludge deposit (SD), and of (b) COR samples with inflow suspended solids $\left(\mathrm{SS}_{\mathrm{i}}\right)$, suspended solids at the outlet of the biological trickling filter $\left(\mathrm{SS}_{\mathrm{TF}}\right)$, suspended solids after $\mathrm{FeCl}_{3}$ injection $\left(\mathrm{SS}_{\mathrm{TF}-\mathrm{Fe}}\right)$, and sludge deposit (SD). 
It appears that the spectra obtained from both plants respectively for $\mathrm{SS}_{\mathrm{i}}$ and $\mathrm{SD}$ showed a relatively common signature, confirming that the composition of POM in wastewater suspended solids on the one hand, and in the sludge deposits on the other hand was very similar regardless of the plant of origin as discussed above.

The FTIR spectra of $\mathrm{SS}_{\mathrm{i}}$ exhibited a broad intense band with a maximum at $3350 \mathrm{~cm}^{-1}$ which is usually associated to the stretching vibration of bonded and non-bonded hydroxyl groups ( $\mathrm{vOH})$ (Haberhauer et al., 1998). This functional group can be found in mineral hydroxides and oxyhydroxides, and in organic compounds (Laurent et al., 2009) such as cellulose (Cocozza et al., 2003), phenols and carboxylic groups (Lv et al., 2013). The presence of water also impacts this band (Ouatmane et al., 2000; Simkovic et al., 2008). Bands between 2950 and $2800 \mathrm{~cm}^{-1}$ were associated to the stretching vibrations of alkyl chains or/and aliphatic methyl and methylene groups $\left(\mathrm{v}_{\mathrm{CH} 2}\right)$ (Ellerbrock et al., 2005; Smidt \& Lechner, 2005), with the stretching vibration of anti-symmetric $\mathrm{CH}_{2}$ group at $2919 \mathrm{~cm}^{-1}$ and the stretching vibration of the symmetric $\mathrm{CH}_{2}$ group at $2851 \mathrm{~cm}^{-1}$. These bands correspond to organic compounds (Laurent et al., 2009) such as hydrocarbons, lipids and related compounds (Cocozza et al., 2003; Niemeyer et al., 1992).

The presence of organic compounds is confirmed with absorption bands in the range between 1800 and $1200 \mathrm{~cm}^{-1}$. Indeed, the band at $1734 \mathrm{~cm}^{-1}$ corresponds to $\mathrm{C}=\mathrm{O}$ stretching $\left(\mathrm{v}_{\mathrm{C}=\mathrm{O}}\right)(\mathrm{Kim}$ \& Yu, 2005), representative of carboxylic acids and aromatic esters (Haberhauer et al., 1998; Laurent et al., 2009; Niemeyer et al., 1992). The broad band at $1634 \mathrm{~cm}^{-1}$ may be assigned to asymmetric stretching of $\mathrm{C}=\mathrm{O}\left(v_{\mathrm{C}=\mathrm{O}}\right)$ in carboxylates and aromatic structures (Ellerbrock \& Kaiser, 2005; Li et al., 2011; Romero et al., 2007). Water OH bending vibration, often observed in inorganic compounds at $1630 \mathrm{~cm}^{-1}$, may also contribute (Gautier et al., 2009). The band at $1574 \mathrm{~cm}^{-1}$ may be attributed to $\mathrm{C}=\mathrm{O}$ stretching vibrations $\left(\mathrm{v}_{\mathrm{C}}=\mathrm{O}\right)$ in ketones and quinones $(\mathrm{Kim}$ $\& \mathrm{Yu}, 2005)$. At $1538 \mathrm{~cm}^{-1}$, the stretching and deformation vibration of $\mathrm{N}-\mathrm{H}$ plane (amide II) 
$\left(v_{\mathrm{N}-\mathrm{H}} ; \delta_{\mathrm{N}-\mathrm{H}}\right)$ may be related to the presence of proteins (Ibarra et al., 1996; Laurent et al., 2009; Zaccheo et al., 2002). The bands at $1468 \mathrm{~cm}^{-1}$ and $1419 \mathrm{~cm}^{-1}$ may be assigned to $\mathrm{C}-\mathrm{H}$ deformation of aliphatic compounds $\left(\delta_{\mathrm{C}-\mathrm{H}}\right)(\mathrm{Kim} \& \mathrm{Yu}, 2005)$. The bands at $1378 \mathrm{~cm}^{-1}$ and 1313 $\mathrm{cm}^{-1}$ correspond to the angular distortion of $\mathrm{CH}$ bond in methyl esters and $\mathrm{C}-\mathrm{N}$ stretching, in aromatic primary and secondary amines $\left(v_{\mathrm{C}-\mathrm{N}}\right)(\mathrm{Lv}$ et al., 2013), respectively.

The band at $1238 \mathrm{~cm}^{-1}$ corresponds to the deformation vibration of $\mathrm{C}=\mathrm{O}(\delta \mathrm{C}=\mathrm{O})$ and $/$ or the stretching vibration of $\mathrm{O}-\mathrm{H}(\delta \mathrm{O}-\mathrm{H})$, characteristics of carboxylic acids and phenol (Laurent et al., 2009). The bands between 1180 and $900 \mathrm{~cm}^{-1}$ may be related to Si-O stretching in mineral phases (Haberhauer et al., 2000; Jouraiphy et al., 2005), but C-O stretching of polysaccharidelike substances (Fernandez et al., 2012), carbohydrate, aromatic ethers (Jouraiphy et al., 2005; Laurent et al., 2009) and alcoholic compounds (Kim \& Yu, 2005) may also contribute.

Fig. 7 showed that in both plants, the intensities of the bands at $2919 \mathrm{~cm}^{-1}, 2851 \mathrm{~cm}^{-1}(\mathrm{vCH} 2)$, $1574 \mathrm{~cm}^{-1}\left(\mathrm{vC}_{\mathrm{C}} \mathrm{O}\right), 1538 \mathrm{~cm}^{-1}\left(\mathrm{v}_{\mathrm{N}-\mathrm{H}} ; \delta_{\mathrm{N}-\mathrm{H}}\right), 1466 \mathrm{~cm}^{-1}\left(\delta_{\mathrm{C}-\mathrm{H}}\right), 1313 \mathrm{~cm}^{-1}(\mathrm{vC}-\mathrm{N})$ and, to a smaller extent $1417 \mathrm{~cm}^{-1}\left(\delta_{\mathrm{C}-\mathrm{H}}\right)$, were larger in $\mathrm{SS}_{\mathrm{i}}$ than in $\mathrm{SD}$ spectra. This result was related to the hydrolysis and mineralization of POM along the treatment chain from $\mathrm{SS}_{\mathrm{i}}$ to SD. Ageing of sludge deposits within the sludge blanket was also confirmed since these bands were of smaller intensities in SD samples from the younger plant COR as compared to the older one VER.

Unlike these bands, those at $1634 \mathrm{~cm}^{-1}$ and $1238 \mathrm{~cm}^{-1}$, respectively assigned to asymmetric stretching of $\mathrm{C}=\mathrm{O}\left(\mathrm{v}_{\mathrm{C}=\mathrm{O}}\right)$ in carboxylates and aromatic structures and deformation vibration of $\mathrm{C}=\mathrm{O}\left(\delta_{\mathrm{C}=\mathrm{O}}\right)$ or stretching vibration of $\mathrm{O}-\mathrm{H}\left(\delta_{\mathrm{O}-\mathrm{H}}\right)$, were found not to decrease and even slightly increased between $\mathrm{SS}_{\mathrm{i}}$ and $\mathrm{SD}$ in both plants. These bounds typically reveal the presence of humic substances thereby confirming the phenomenon of POM humifaction already revealed by $3 \mathrm{D}$ fluorescence analyses (Figs $5 \mathrm{c}$ and 6 ). 
A slight decrease of the bands at $1574,1466,1417 \mathrm{~cm}^{-1}$ was observed at the trickling filter stage (SSTF samples) in COR plant, indicating a reduction of the contents in quinone, ketone, and aliphatic compounds respectively. This finding was consistent with the results from thermal analysis which already showed the major effects of the trickling filter. Conversely, a slight relative increase of the bands at $1634 \mathrm{~cm}^{-1}$ and $1238 \mathrm{~cm}^{-1}$ was observed at the trickling filter stage, confirming the effect of the trickling filter in the formation of carboxylic acids and therefore in the aerobic mineralization of POM discussed above. After $\mathrm{FeCl}_{3}$ injection $\left(\mathrm{SS}_{\mathrm{TF}-\mathrm{Fe}}\right.$ samples), a strong decrease in the intensity of the band at $1538 \mathrm{~cm}^{-1}$ was observed, revealing a decrease in $\mathrm{N}-\mathrm{H}$ groups notably present in amino-acids, peptides and proteins.

\subsection{Isotopic analyses}

The average values of $\delta^{13} \mathrm{C}, \delta^{15} \mathrm{~N}$, and $\delta^{2} \mathrm{H}$ isotopic ratios measured in the different samples are gathered in Fig. 8. It can firstly be seen that the suspended solids on the one hand and the sludge deposits on the other hand revealed very close isotopic compositions regardless of the plant of origin, as already observed above with respect to the other parameters analyzed in this study.

In both treatment plants, $\delta^{13} \mathrm{C}$ values were also found to be the same in $\mathrm{SS}_{\mathrm{i}}$ and $\mathrm{SD}$ samples. The recorded values ranged between $-26.5 \%$ and $-26.3 \%$ which is the typical range recorded in natural OM derived from C3 photosynthetic pathway (Fernandez et al., 2003). This parameter was therefore not identified here as a good indicator of the evolution of POM in the investigated system.

$\delta^{15} \mathrm{~N}$ ratio was found to be more relevant than $\delta^{13} \mathrm{C}$ as an indicator of POM evolution. $\delta^{15} \mathrm{~N}$ ratio was found to be higher in SD samples $(6.10 \pm 0.31 \%$ and $5.98 \pm 0.46 \%$ in VER and COR treatment plants, respectively) than in $\mathrm{SS}_{\mathrm{i}}(4.8 \pm 0.3 \%$ and $2.2 \pm 0.3 \%$ \%o in VER and COR, respectively). This finding was related to the microbial processes of hydrolysis and mineralization of POM. Due to their lower energy, the $\mathrm{C}-{ }^{14} \mathrm{~N}$ bounds were lysed preferentially 
by the microbial catabolism as compared to $\mathrm{C}-{ }^{15} \mathrm{~N}$ bounds, resulting in a progressive enrichment of the heavy isotope ${ }^{15} \mathrm{~N}$ within the residual POM (De Clercq et al., 2015; Novak et al., 2014). This observation was already reported in several natural media such as forest soils (Hobbie \& Ouimette, 2009; Novak et al., 1996).

$\delta^{2} \mathrm{H}$ ratio was also found to be higher (less negative) in SD samples $(-80 \pm 9 \%$ and $-71 \pm 7 \%$ in VER and COR treatment plants, respectively) than in $\mathrm{SS}_{\mathrm{i}}(-121 \pm 13 \%$ and $-101 \pm 11 \%$ in VER and COR, respectively). The increase in $\delta^{2} \mathrm{H}$ ratio in natural media was already observed by other authors and related to an increase in the stability and maturity of organic matter (Schimmelmann et al., 2006). The increase observed here was therefore considered to provide an additional evidence of the humifaction of POM, first along the treatment chain in parallel with the major mechanisms of hydrolysis and mineralization, and then, more notably, during the ageing of surface deposits within the surface sludge. $\delta^{15} \mathrm{~N}$ and $\delta^{2} \mathrm{H}$ isotopic ratios were therefore identified as good indicators of POM evolutions in French VFCWs.

The monitoring of $\delta^{15} \mathrm{~N}$ and $\delta^{2} \mathrm{H}$ isotopic ratios in the particulate samples taken along the treatment chain from COR treatment plant $\left(\mathrm{SS}_{\mathrm{i}}, \mathrm{SS}_{\mathrm{TF}-\mathrm{Fe}}, \mathrm{SS}_{\mathrm{TF}-\mathrm{Fe}}\right.$ and $\mathrm{SD}$ samples, respectively) showed that the aerobic treatment on the biological trickling filter was the stage where the strongest changes were observed (Fig. 8b). The evolutions recorded in $\delta^{15} \mathrm{~N}$ and $\delta^{2} \mathrm{H}$ isotopic ratios revealed the same patterns as observed with other analytical parameters reported above in the article, such as SEOM contents (Fig. 4b) and $\mathrm{R}_{\mathrm{TGA}}$ index in Table 2. 
(a) VER

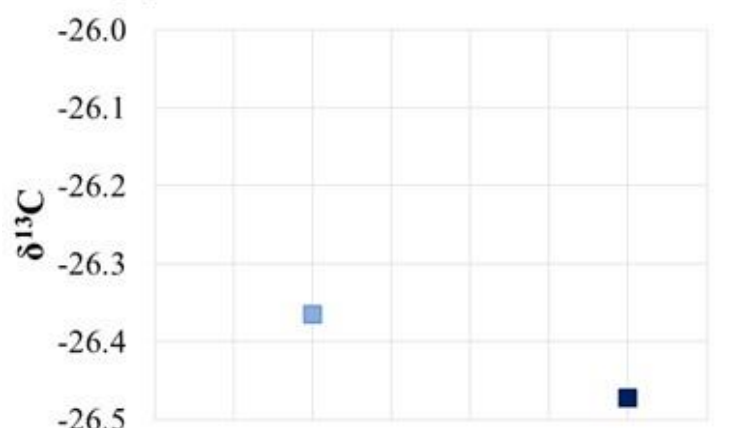

$-26.5$
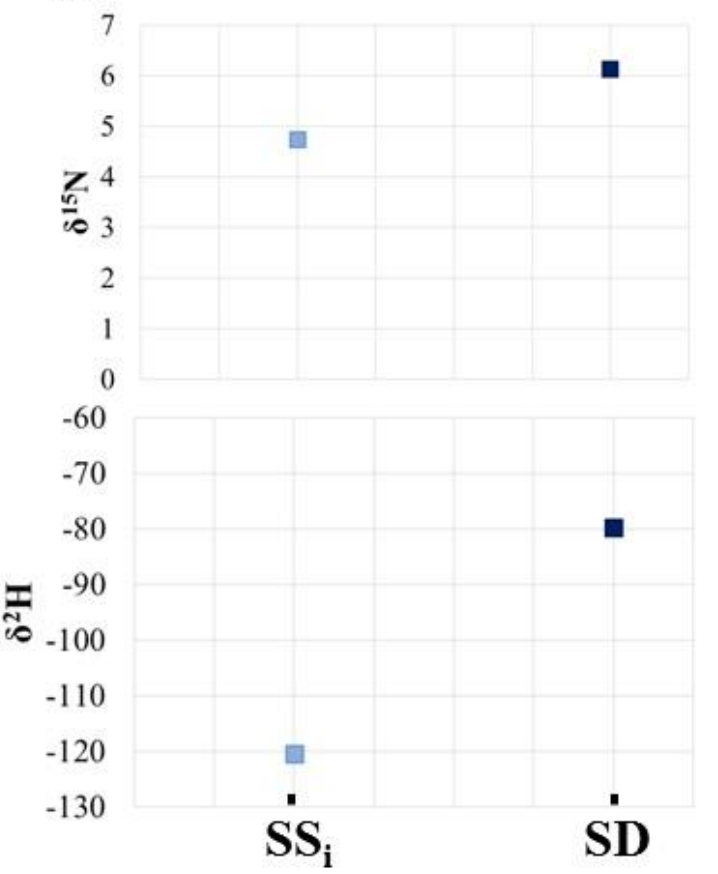

(b) COR
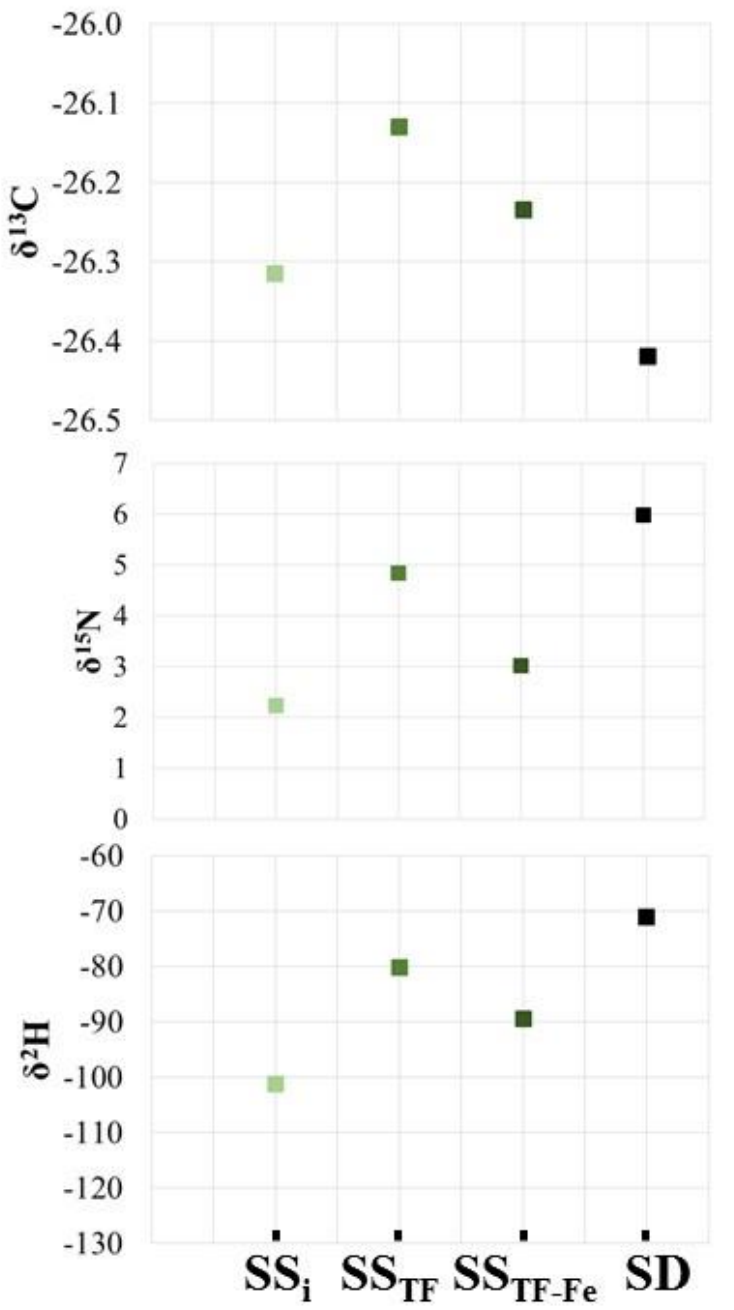

Fig. 8: $\mathrm{C}$ isotopic ratio (top), $\mathrm{N}$ isotopic ratio (middle) and $\mathrm{H}$ isotopic ratio (bottom) profiles for the suspended solids and sludge deposits SD from (a) VER plant and (b) COR plant. 


\section{Conclusion}

The four analytical methods allowed to have information both on the nature of the organic matter but also its evolution throughout the treatment chain. Indeed, the thermal analysis indicated that the POM resulting from the inflow domestic wastewater consisted essentially of reactive, relatively oxidized biodegradable constituents. On the contrary, the POM resulting from the sludge deposit was constituted of both an easily biodegradable organic matter and also thermally stable compounds. This suggested the humification process over time on the filter. This observation was confirmed by the use of the 3D fluorescence EEM analysis, which showed an evolution of the $\mathrm{OM}$ from low-molecular reactive compounds to more complex and stable structures as humic-like substances, but also by the FTIR analysis, shown by the increase of the bands at $1634 \mathrm{~cm}^{-1}\left(\mathrm{vC}_{\mathrm{C}} \mathrm{O}\right)$ and $1238 \mathrm{~cm}^{-1}\left(\delta_{\mathrm{C}=\mathrm{O}}\right.$ and $/$ or $\left.\delta \mathrm{OH}\right)$ in the sludge deposit.

The isotopic approach was a first for this type of system. It was observed that the $\delta^{15} \mathrm{~N}$ and $\delta^{2} \mathrm{H}$ isotopic ratios were good indicators for studying the evolution of OM. It has been shown that the increase of the $\delta^{2} \mathrm{H}$ ratio between the SS and the sludge was synonymous with the humification process. The ratio $\delta^{15} \mathrm{~N}$ clearly showed the microbial processes of hydrolysis and mineralization.

All the analyzes carried out along the treatment chain were agreed on the importance of the trickling filter on the $\mathrm{OM}$ transformation, and in a second measure the $\mathrm{FeCl}_{3}$ addition. Indeed, thermal analyzes showed hydrolysis and partial mineralization of inflow wastewater compounds through TF, which was confirmed by FTIR analysis, with a decrease in the intensity of the bands $2919 \mathrm{~cm}^{-1}, 2851 \mathrm{~cm}^{-1}\left(\mathrm{v}_{\mathrm{CH}}\right), 1574 \mathrm{~cm}^{-1}\left(\mathrm{v}_{\mathrm{C}=\mathrm{O}}\right), 1538 \mathrm{~cm}^{-1}\left(\mathrm{v}_{\mathrm{N}-\mathrm{H}} ; \delta_{\mathrm{N}-\mathrm{H}}\right), 1466 \mathrm{~cm}^{-1}$ $(\delta \mathrm{C}-\mathrm{H})$ and $1313 \mathrm{~cm}^{-1}(\mathrm{VC}-\mathrm{N})$. The analysis of 3D fluorescence EEM showed the impact of $\mathrm{FeCl}_{3}$ on the change in the nature of organic matter: the oxidation by Fe (III) of small molecules, like proteins, was associated with the enrichment of substance type humic- like, or the coagulation 
effect of $\mathrm{FeCl}_{3}$ on the $\mathrm{OM}$ particles. This decrease in protein-like molecules was also observed with the FTIR analysis.

This study clearly shows the complementarity of the analyzes carried out. However, advantages and disadvantages for each analysis can be emphasized. The TGA, FTIR and isotopy allow to carry out the analysis directly on the solid sample, on the contrary an extraction step is necessary for the 3D Fluorsecence EEM spectroscopy. However, the four methods allow analysis on small sample quantities. The TGA gives only a global view of the compounds found in the samples, whereas 3D Fluorsecence EEM spectroscopy and FTIR can be more precise analyzes on the type of compound found. The isotopy seems to be a "promising" analysis but has to be consolidated on this type of matrix.

\section{Acknowledgements}

The authors would like to thank ISA (Institut des Sciences Analytiques) for the isotopic analyses, the laboratory for Solid Waste Management and Environment Safety in tTsinghua University for the 3D fluorescence EEM analyses and the OSUC (Observatoire des Sciences de l'Univers en région Centre) for the FTIR analyses. They are also grateful to SCIRPE and CIFRE (Conventions Industrielles de Formation pour la REcherche) for funding this research project.

\section{References}

Baccot, C. 2016. Etude du potentiel de valorisation énergétiquevou matière de composés organiques extraits de lixiviats de déchets ménagers (Study of the potential of energy recovery or of organic compounds extracted from household waste leachates). PhD thesis, Environmental Sciences, University of Limoges - Limoges, France, 1-319.

Chen, J., Mu, L., Cai, J., Yin, H., Song, X., Li, A. 2015. Thermal characteristics and kinetics of refining and chemicals wastewater, lignite and their blends during combustion. Energy Conversion and Management, 100, 201-211.

Chen, W., Westerhoff, P., Leenheer, J.A., Booksh, K. 2003. Fluorescence Excitation-Emission matrix integration to quantify spectra for dissolved organic matter. Environmental science \& technology, 37, $5701-5710$.

Cocozza, C., D'Orazio, V., Miano, T.M., Shotyk, W. 2003. Characterization of solid and aqueous phases of a peat bog profile using molecular fluorescence spectroscopy, ESR and FT-IR, and comparison with physical properties. Organic Geochemistry, 34, 49-60. 
Cuypers, C., Grotenhuis, T., Nierop, K.G.J., Maneiro Franco, E., De Jager, A., Rulkens, W. 2002. Amorphous and condensed organic matter domains: the effect of persulfate oxidation on the composition of soil/sediment organic matter. Chemosphere, 48, 919-931.

De Clercq, T., Heiling, M., Dercon, G., Resch, C., Aigner, M., Mayer, L., Mao, Y., Elsen, A., Steier, P., Leifeld, J., Merckx, R. 2015. Predicting soil organic matter stability in agricultural fields through carbon and nitrogen stable isotopes. Soil Biology and Biochemistry, 88, 29-38.

Ellerbrock, R.H., Gerke, H.H., Bachmann, J., Goebel, M.-O. 2005. Composition of organic matter fractions for explaining wettability of three forest soils. Soil Science Society of America Journal, 69, 57-66.

Ellerbrock, R.H., Kaiser, M. 2005. Stability and composition of different soluble soil organic matter fractions-evidence from $\delta 13 \mathrm{C}$ and FTIR signatures. Geoderma, 128(1-2), 28-37.

Fernandez, I., Mahieu, N., Cadisch, G. 2003. Carbon isotopic fractionation during decomposition of plant materials of different quality. Global Biogeochemical Cycles, 17(3), n/a-n/a.

Fernandez, J.M., Plaza, C., Polo, A., Plante, A.F. 2012. Use of thermal analysis techniques (TG-DSC) for the characterization of diverse organic municipal waste streams to predict biological stability prior to land application. Waste management, 32(1), 158-64.

Fu, G., Guo, Z., Zhang, J., Chen, Z., Wong, M.-H. 2015. Organic matter transplant improved purification performance of newly built constructed wetlands. Ecological Engineering, $\mathbf{8 3}$ 338-342.

Gautier, M., Muller, F., Beny, J.M., Forestier, L.L., Alberic, P., Baillif, P. 2009. Interactions of ammonium smectite with low-molecular-weight carboxylic acids. Clay Minerals, 44(2), 207219.

Gomez, X., Cuetos, M.J., Garcia, A.I., Moran, A. 2007. An evaluation of stability by thermogravimetric analysis of digestate obtained from different biowastes. Journal of hazardous materials, 149(1), 97-105.

Gomez, X., Cuetos, M.J., García, A.I., Morán, A. 2005. Evaluation of digestate stability from anaerobic process by thermogravimetric analysis. Thermochimica Acta, 426(1-2), 179-184.

Haberhauer, G., Feigl, B., Gerzabek, M.H., Cerri, C. 2000. FT-IR spectroscopy of organic matter in tropical soils: changes induced through deforestation. Applied Spectroscopy, 54, 221-224.

Haberhauer, G., Rafferty, B., Strebl, F., Gerzabek, M.H. 1998. Comparison of the composition of forest soil litter derived from three different sites at various decompositional stages using FTIR spectroscopy. Geoderma, 83, 331-342.

He, X.S., Xi, B.D., Wei, Z.M., Jiang, Y.H., Yang, Y., An, D., Cao, J.L., Liu, H.L. 2011. Fluorescence excitation-emission matrix spectroscopy with regional integration analysis for characterizing composition and transformation of dissolved organic matter in landfill leachates. Journal of hazardous materials, 190(1-3), 293-9.

Hobbie, E.A., Ouimette, A.P. 2009. Controls of nitrogen isotope patterns in soil profiles. Biogeochemistry, 95(2-3), 355-371.

Ibarra, J.V., Munoz, E., Moliner, R. 1996. FTIR study of the evolution of coal structure during the coalification process. Organic Geochemistry, 24, 725-735.

Jimenez, J., Aemig, Q., Doussiet, N., Steyer, J.P., Houot, S., Patureau, D. 2015. A new organic matter fractionation methodology for organic wastes: Bioaccessibility and complexity characterization for treatment optimization. Bioresource technology, 194, 344-53.

Jimenez, J., Gonidec, E., Cacho Rivero, J.A., Latrille, E., Vedrenne, F., Steyer, J.P. 2014. Prediction of anaerobic biodegradability and bioaccessibility of municipal sludge by coupling sequential extractions with fluorescence spectroscopy: towards ADM1 variables characterization. Water research, 50, 359-72.

Jouraiphy, A., Amir, S., El Gharous, M., Revel, J.-C., Hafidi, M. 2005. Chemical and spectroscopic analysis of organic matter transformation during composting of sewage sludge and green plant waste. International Biodeterioration \& Biodegradation, 56(2), 101-108.

Kim, B., Gautier, M., Michel, P., Gourdon, R. 2013. Physical-chemical characterization of sludge and granular materials from a vertical flow constructed wetland for municipal wastewater treatment. Water Science and Technology 68, 2257-63.

Kim, B., Gautier, M., Prost-Boucle, S., Molle, P., Michel, P., Gourdon, R. 2014. Performance evaluation of partially saturated vertical-flow constructed wetland with trickling filter and 
chemical precipitation for domestic and winery wastewaters treatment. Ecological Engineering, 71, 41-47.

Kim, H.C., Yu, M.J. 2005. Characterization of natural organic matter in conventional water treatment processes for selection of treatment processes focused on DBPs control. Water research, 39(19), 4779-89.

Kogel-Knabner, I. 2000. Analytical approaches for characterizing soil organic matter. Organic Geochemistry, 31, 609-625.

Laurent, J., Casellas, M., Pons, M.N., Dagot, C. 2009. Flocs surface functionality assessment of sonicated activated sludge in relation with physico-chemical properties. Ultrasonics sonochemistry, 16(4), 488-94.

Li, X., Xing, M., Yang, J., Huang, Z. 2011. Compositional and functional features of humic acid-like fractions from vermicomposting of sewage sludge and cow dung. Journal of hazardous materials, 185(2-3), 740-8.

Lu, X., Zhen, G., Estrada, A.L., Chen, M., Ni, J., Hojo, T., Kubota, K., Li, Y.Y. 2015. Operation performance and granule characterization of upflow anaerobic sludge blanket (UASB) reactor treating wastewater with starch as the sole carbon source. Bioresource technology, 180, 26473.

Lv, B., Xing, M., Yang, J., Qi, W., Lu, Y. 2013. Chemical and spectroscopic characterization of water extractable organic matter during vermicomposting of cattle dung. Bioresource technology, 132, 320-6.

Magdziarz, A., Wilk, M. 2013. Thermogravimetric study of biomass, sewage sludge and coal combustion. Energy Conversion and Management, 75, 425-430.

Marhuenda-Egea, F.C., Martinez-Sabater, E., Jorda, J., Moral, R., Bustamante, M.A., Paredes, C., Perez-Murcia, M.D. 2007. Dissolved organic matter fractions formed during composting of winery and distillery residues: evaluation of the process by fluorescence excitation-emission matrix. Chemosphere, 68(2), 301-9.

Melis, P., Castaldi, P. 2004. Thermal analysis for the evaluation of the organic matter evolution during municipal solid waste aerobic composting process. Thermochimica Acta, 413(1-2), 209-214.

Molle, P. 2014. French vertical flow constructed wetlands: a need of a better understanding of the role of the deposit layer. Water Science and Technology, 69(1), 106-12.

Niemeyer, J., Chen, Y., Bollag, J.M. 1992. Characterization of humic acids, composts, and peat by diffuse reflectance Fourier-Transform infrared-spectroscopy. Soil Science Society of America Journal, 56, 135-140.

Novak, M., Bottrell, S.H., Fottova, D., Buzek, F., Groscheva, H., Karel, Z. 1996. Sulfur isotope signals in forest soils of Central Europe along an air pollution gradient. Environmental science \& technology, 30, 3473-3476.

Novak, M., Stepanova, M., Jackova, I., Vile, M.A., Wieder, R.K., Buzek, F., Adamova, M., Erbanova, L., Fottova, D., Komarek, A. 2014. Isotopic evidence for nitrogen mobility in peat bogs. Geochimica et Cosmochimica Acta, 133, 351-361.

Otero, M., Calvo, L.F., Estrada, B., García, A.I., Moran, A. 2002. Thermogravimetry as a technique for establishing the stabilization progress of sludge from wastewater treatment plants. Thermochimica Acta, 389, 121-132.

Ouatmane, A., Provenzano, M.R., Hafidi, M., Senesi, N. 2000. Compost Maturity Assessment Using Calorimetry, Spectroscopy and Chemical Analysis. Compost Science \& Utilization, 8(2), 124134.

Romero, E., Plaza, C., Senesi, N., Nogales, R., Polo, A. 2007. Humic acid-like fractions in raw and vermicomposted winery and distillery wastes. Geoderma, 139(3-4), 397-406.

Schimmelmann, A., Sessions, A.L., Mastalerz, M. 2006. Hydrogen isotopic (D/H) composition of organic matter during diagenesis and thermal maturation. Annual review of Earth and Planetary Sciences 34, 501-533.

Sheng, G.P., Yu, H.Q. 2006. Characterization of extracellular polymeric substances of aerobic and anaerobic sludge using three-dimensional excitation and emission matrix fluorescence spectroscopy. Water research, 40(6), 1233-9. 
Simkovic, I., Dlapa, P., Doerr, S.H., Mataix-Solera, J., Sasinkova, V. 2008. Thermal destruction of soil water repellency and associated changes to soil organic matter as observed by FTIR spectroscopy. Catena, 74(3), 205-211.

Smidt, E., Lechner, P. 2005. Study on the degradation and stabilization of organic matter in waste by means of thermal analyses. Thermochimica Acta, 438(1-2), 22-28.

Som, M.P., Lemee, L., Ambles, A. 2009. Stability and maturity of a green waste and biowaste compost assessed on the basis of a molecular study using spectroscopy, thermal analysis, thermodesorption and thermochemolysis. Bioresource technology, 100(19), 4404-16.

Torres-Climent, A., Gomis, P., Martin-Mata, J., Bustamante, M.A., Marhuenda-Egea, F.C., PerezMurcia, M.D., Perez-Espinosa, A., Paredes, C., Moral, R. 2015. Chemical, Thermal and Spectroscopic Methods to Assess Biodegradation of Winery-Distillery Wastes during Composting. PloS one, 10(9), e0138925.

Wei, Z., Wang, X., Zhao, X., Xi, B., Wei, Y., Zhang, X., Zhao, Y. 2016. Fluorescence characteristics of molecular weight fractions of dissolved organic matter derived from composts. International Biodeterioration \& Biodegradation, 113, 187-194.

Zaccheo, P., Cabassi, G., Ricca, G., Crippa, L. 2002. Decomposition of organic residues in soil: experimental technique and spectroscopic approach. Organic Geochemistry, 33, 327-345.

Zahra El Ouaqoudi, F., El Fels, L., Lemée, L., Amblès, A., Hafidi, M. 2015. Evaluation of lignocelullose compost stability and maturity using spectroscopic (FTIR) and thermal (TGA/TDA) analysis. Ecological Engineering, 75, 217-222.

(REF dont Bayard, R. ; Gachet, C. ; Achour, F. ; de Brauer, C. \& Gourdon, R. (2005). Organic matter stabilization of MSW sorted waste under simulation bioreactors. Tenth international waste management and landfill symposium, Cagliari, Italie, October 2005.). 